\title{
A Five-Band Recording Spectroradiometer
}

\author{
C. S. McCamy
}

\begin{abstract}
In a project ${ }^{1}$ undertaken to determine the properties of flames that might be utilized in the detection of accidental fires in aircraft engine compartments, an instrument was constructed to measure and record the radiant energy emitted by flames in five separate wavelength regions from 0.23 to 2.5 microns. The radiant intensity of several types of hydrocarbon flames was determined in each spectral region. The frequency distribution of the fluctuations in the radiant intensity (flicker) was also determined.
\end{abstract}

\section{Introduction}

An accidental fire in an aircraft engine compartment can be dealt with successfully only if the fire is detected within a few seconds after it starts. Many methods of detecting such fires have been devised but most of them have been unsatisfactory, primarily because of inadequate coverage and false alarms. Because it is so difficult to predict where accidental flames will strike, devices that require flame contact can be properly placed only after actual fire test in a typical installation. Because accidental fires may occur in many places, an excessive number of such detectors is required for adequate coverage.

Devices that respond to the radiant energy from flames have received considerable attention because a single unit can detect fires anywhere within a large space. Such detectors must, of course, be able to discriminate between the radiant energy from flames and that from the sun or hot engine parts. To accomplish this, the use of two characteristics of flame radiation has been proposed: the spectral distribution of the energy and the fluctuations in the radiant intensity known as "flicker."

Most accidental engine fires involve the burning of hydrocarbons. Although most of the radiation from the flames is in the near infrared, there is a small amount in the visible spectrum and in the ultraviolet. Because hot engine parts radiate practically no energy in the ultraviolet, and because the ozone in the earth's upper atmosphere filters out solar radiation of wavelengths below $0.29 \mu$, this region is free of interference from these sources. A detector employing a Geiger-Müller-type photon counter, which is sensitive in a part of this spectral region only, has been patented [1]. ${ }^{2}$ However, difficulties such as the ultraviolet absorptance of the oil films inevitable in engine spaces have, so far, prevented the use of this part of the spectrum.

The characteristic flicker of flames has been used to distinguish them by another system that operates in the near infrared [2]. Unfortunately, the effec-

\footnotetext{
1. This work was sponsored by the Wright Air Development Center, Air Research and Development Command.

2 Figures in brackets indicate the literature references at the end of this paper.
}

tiveness of the lead-sulfide cell used to detect radiation in this system is greatly diminished at the high ambient temperatures encountered in engine spaces.

It appeared that other parts of the spectrum or other flame characteristics might be found more useful. In order to explore some of the possibilities, an instrument was built to record the radiant intensity of flames in several broad regions of the spectrum and to determine the frequency distribution of the flicker in each region.

\section{Design Considerations}

Five regions of the spectrum were selected on the basis of the following considerations: Because even a thin layer of air absorbs practically all ultraviolet radiation at wavelengths shorter than $0.18 \mu$, this region appeared to be of no significance in fire detection. The region just below $0.29 \mu$ was of particular interest because, as noted earlier, it is practically free of solar and thermal-radiation interference. Hence, one of the regions chosen was that between 0.23 and $0.29 \mu$. Two regions were selected in the visible spectrum, the blue region from 0.41 to $0.55 \mu$ and the yellow region from 0.55 to $0.70 \mu$. These were selected so that the instrument might differentiate between blue flames, which usually occur when the fuel is premixed with air, and yellow flames, which usually occur when the air is merely allowed to diffuse into the flame. The infrared region selected extended from the red end of the visible spectrum, $0.70 \mu$, to the long wavelength limit of sensitivity of the sensing element, $2.5 \mu$. The remaining ultraviolet region from 0.30 to $0.41 \mu$ was used to complete the spectrum from $0.23 \mu$ in the ultraviolet to $2.5 \mu$ in the infrared. Because the sensitivity of most of the available high-speed photosensitive devices was limited to the five selected regions, it was there that immediate practical applications seemed most likely, even though most of the energy radiated by flames is in the infrared at wavelengths beyond $2.5 \mu$ [3]. Instruments were set up to record the five response signals simultaneously and to measure the frequency and amplitude of the flicker.

The general functional design of the whole instrument is indicated in the block diagram, figure 1 . 


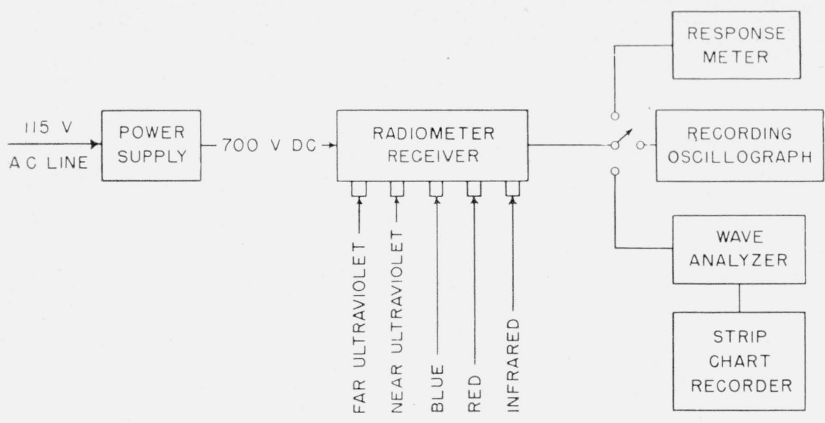

FIGURE 1. Block diagram of spectroradiometer.

\section{Radiometric System}

The receiver consisted of the radiation detectors, resistors for the voltage supply, and optical filters to isolate the wavelength regions, all in a compartmented enclosure. A rear view of the receiver with the back cover removed is shown in figure 2. The sensitive areas of the detectors were placed close together so that a radiant source could be viewed from nearly the same direction by all of them.

Four of the detectors were RCA type 1P28 photomultiplier tubes, the other, used for the infrared region, was a Kodak Ektron, type I, lead sulfide photoconductive cell with a 4 - by 4 -mm sensitive area.

All of the filters were commercially available except the one for the region from 0.23 to $0.29 \mu$. This one was made up of three liquid solutions in fused-quartz cells and a glass filter, as follows: (1) $2 \mathrm{~cm}$ of an aqueous solution containing $30 \mathrm{~g}$ of nickel sulfate per $100 \mathrm{ml},(2) 1 \mathrm{~cm}$ of an aqueous solution of $5 \times$ $10^{-5}$ molar 4,4'-diaminobenzophenone, (3) $1 \mathrm{~cm}$ of an aqueous solution containing $20 \mathrm{mg}$ of 1,4-diazepine2,3-dihydro-5,7-dimethyl perchlorate in $100 \mathrm{ml}$ of solution, and (4) a Corning glass filter, number 7-54.

Kasha [4] used a compound similar to that in the third cell described above to isolate this region but found a small amount of transmission at $0.347 \mu$. The second liquid cell mentioned above was used here to eliminate a corresponding defect at $0.355 \mu$. There was no significant change in transmittance of the filter during 1 year of use.

A Photovolt filter, No. 5264, was used for the region 0.30 to $0.41 \mu$; two Corning filters, Nos. 5-56 and $3-73$, were used for the $0.41-$ to $0.55-\mu$ region; a Corning 3-67 filter covered the $0.55-$ to $0.70-\mu$ region; and a Photovolt filter, No. 5263, was used for the region from 0.70 to $2.5 \mu$.

These filters with the corresponding detectors produced the relative spectral responses shown in figure 3.

The field of view of each of the sections of the instrument was measured. The field angle was defined as the angle subtended at the receiver, in a plane with the normal to the center of the filter, between the opposite positions of a small source angularly displaced to reduce the response to 90 percent of the maximum value. In some cases, the

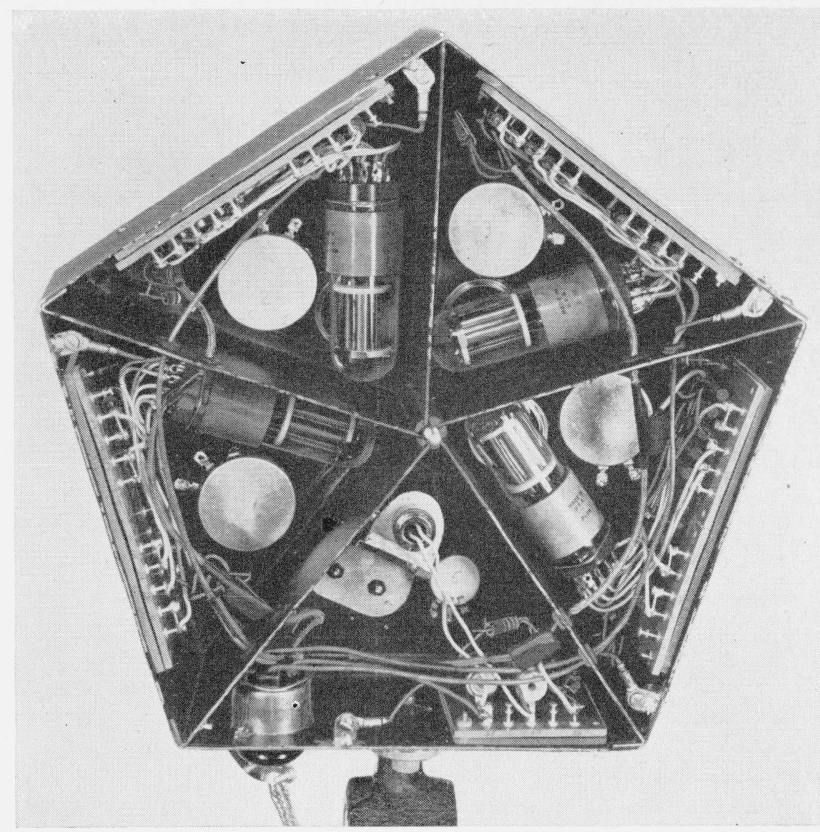

FiguRE 2. Spectroradiometer receiver, rear view of interior.

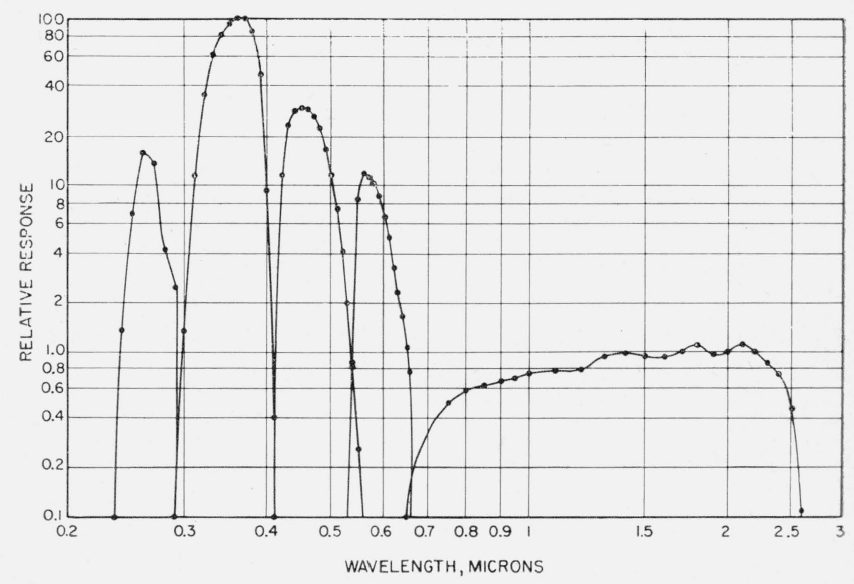

Figure 3. Relative spectral response of the spectroradiometer.

field angle in some planes was greater than the minimum values given below. The field angle for the liquid filter system was about $13^{\circ}$, that for the photomultipliers with glass filters was about $22^{\circ}$, and that for the infrared system was about $30^{\circ}$.

The circuit diagram of the receiver and power supply is given in figure 4 . The high-voltage (plate) transformer was shielded from the other components of the power supply and the connections to this transformer and all output leads were shielded to prevent induced interference. The power supply provided a potential difference of $700 \mathrm{v}$, d-c, with an alternating component of less than 0.001 percent. 


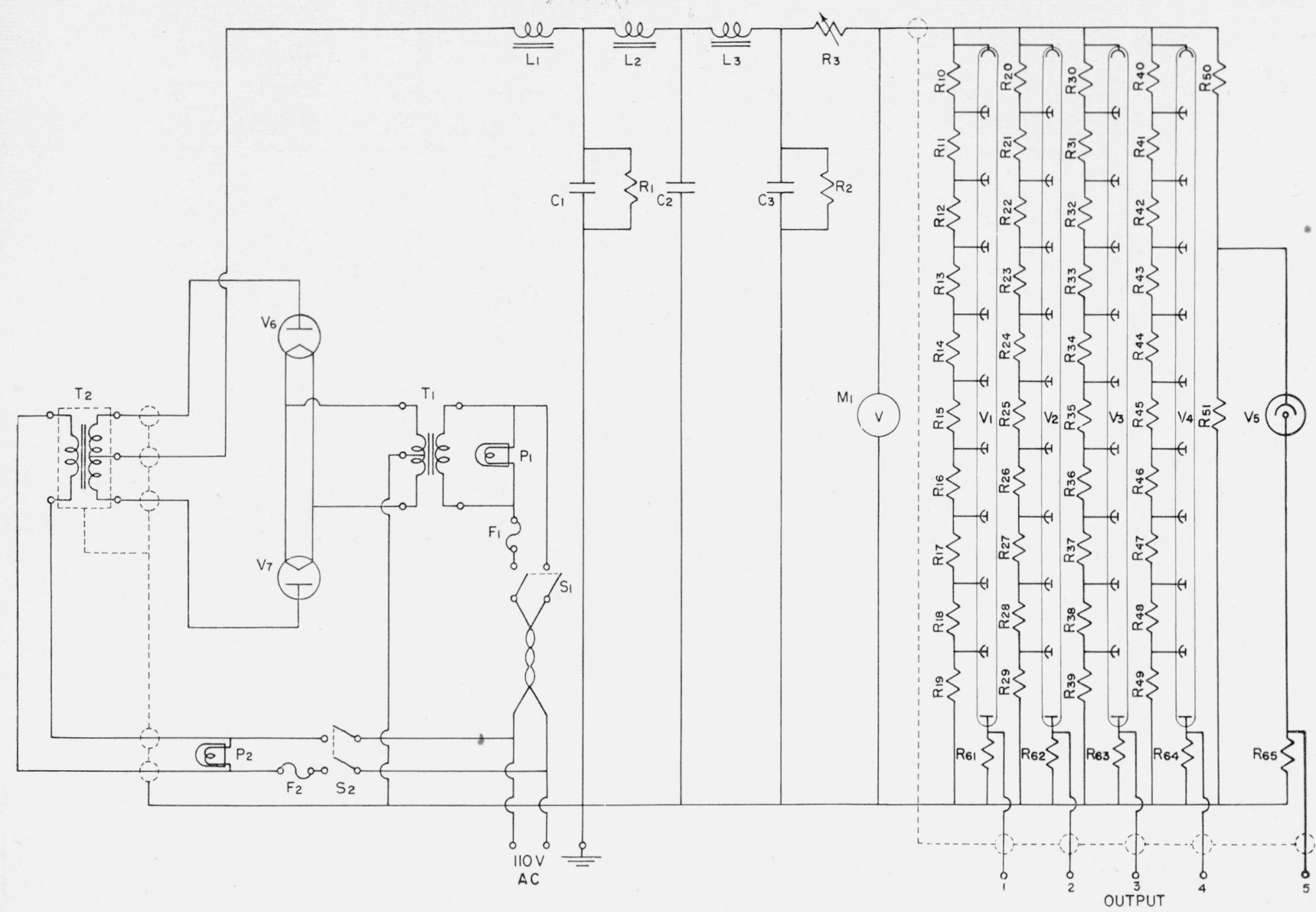

Figure 4. Circuit diagram of power supply and receiver.

$\mathrm{C}_{1}=9 \mu f$.

$\mathrm{C}_{2}=8 \mu f$.

$\mathrm{C}_{3}=16 \mu \mathrm{f}$.

$\mathrm{F}_{1}=3 / 4$-amp fuse.

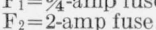

$\mathrm{L}_{1,2,3}=30 \mathrm{~h}, 35 \mathrm{ma}$ de, $2-\mathrm{kv}$ insulation.

$\mathrm{M}_{1}=0$ to 1,500 -v d-c meter.

$\mathrm{M}_{1}=0$ to $1,500-\mathrm{v}$ d-c meter.

$\mathrm{R}_{1}=4.9$ megohms.
$R_{2}=10$ megohms. $R_{3}=0$ to $10,000 \mathrm{ohms}$.

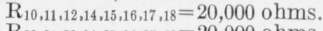

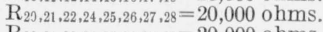

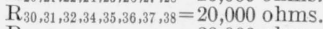

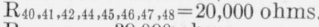

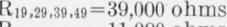
$\mathrm{R}_{13,23,33,43}=11,000$ o.
$\mathrm{R}_{50}=348,000$ ohms.

$\mathrm{R}_{51}=40,000$ ohms, 1 percent, $1 \mathrm{w}$.

$\mathrm{R}_{61,62,63,64}=510 \mathrm{ohms}$.

$\mathrm{R}_{65}=400,000 \mathrm{ohms}, 1 / 2$ percent, $1 \mathrm{w}$.

$\mathrm{S}_{1,2}=$ dpst toggle switch.

$\mathrm{T}_{1}=2,5-\mathrm{v}$ center tap filament transformer, $10 \mathrm{amp}$. $\mathrm{T}_{2}=$ plate transformer $700-0-700 \mathrm{v}, 180 \mathrm{ma}$.

$V_{1,2,3,4}=1$ P28 photomultiplier tubes.

$\mathrm{V}_{5}=$ Kodak Ektron PbS cell, $4 \times 4 \mathrm{~mm}$ $\mathrm{V}_{6,7}=866 \mathrm{~A}$ rectifier tubes.

\section{Auxiliary Equipment}

\subsection{Measuring Equipment}

The block diagram of the instrument shown in figure 1 indicates several ways in which the radiometric response potentials were utilized.

The potentials could be read directly, one at a time, on a suitable millivoltmeter. This method was used during the preparations for experiments and during the radiometric calibration procedure.

In order to obtain a permanent record of the instantaneous values of all five response signals simultaneously, the signals were put into a recording oscillograph [5]. This instrument was essentially a row of 2 -in. cathode-ray oscilloscopes facing a camera in which $35-\mathrm{mm}$ film was continually exposed as it moved at a constant speed of about 2 in. /sec. at right angles to the deflection of the spots on the tubes. A continuous trace was produced for each of the response signals. The output of a fixedfrequency oscillator was connected with one cathoderay tube to provide a time scale. A sample of the record film is shown in figure 5. (On the film shown, the radiant energy indicated on trace $\mathrm{E}$ was so small that the instrument noise appeared quite large when the signal was amplified in the recorder.)

In figure 5 it may be seen that the radiant energy in the five wavelength regions fluctuated with practically the same fundamental frequency. For this reason, the flicker frequency was analyzed in only one region, the infrared region, where most of the energy was found. The response potential was applied to a General Radio type 762-B Vibration Analyzer having a frequency range 2.5 to $750 \mathrm{cps}$. To facilitate the determination of the average amplitude for each frequency, the output of the wave analyzer was continuously recorded. The effect of flicker frequency on the response of the infrared radiometric system was measured. The response 


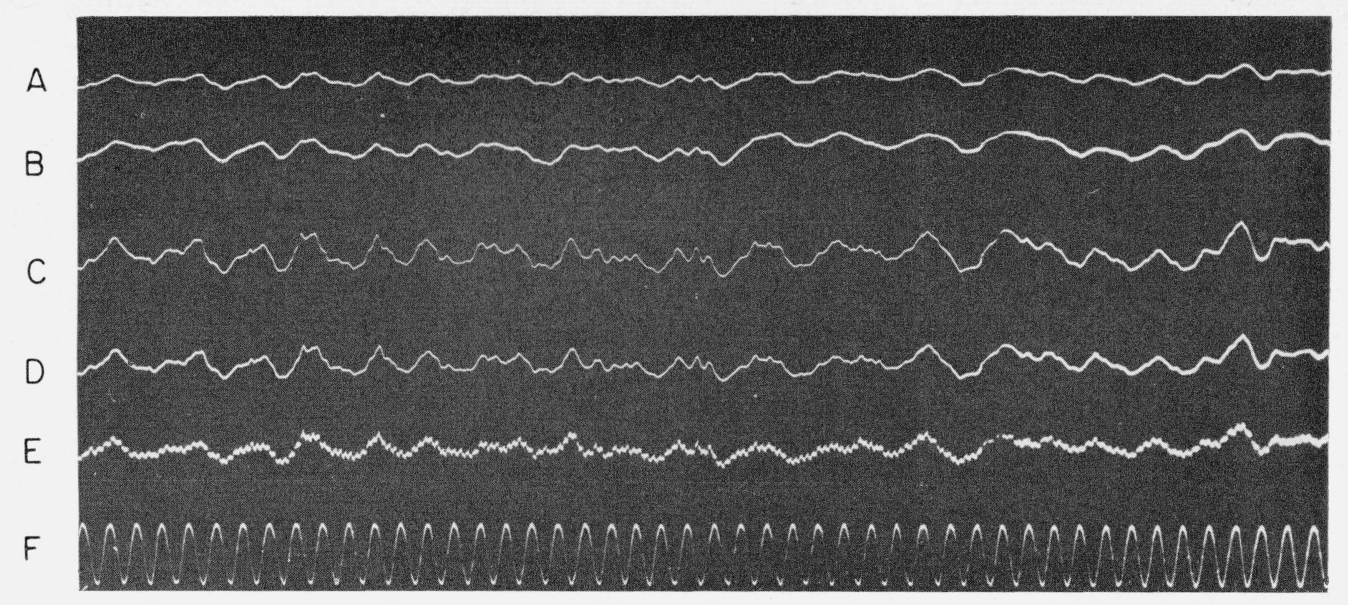

FIGURE 5. Oscillograph record of variations in radiant intensity in five wavelength regions.

$\mathrm{A}, 0.70$ to $2.5 \mu$; B, 0.55 to $0.70 \mu$; C, 0.41 to $0.55 \mu$; D, 0.30 to $0.41 \mu$; E, 0.23 to $0.29 \mu$; F, 40-cps timing trace.

was found to be essentially constant from 1 to 50 cps, and to diminish smoothly to 85 percent at 133 cps and 30 percent at $1,700 \mathrm{cps}$.

\subsection{Burners and Fuels}

The burner used in most of the work was an open stainless-steel cylinder 6 in. in diameter and 2 in. deep, with a water-cooled brass bottom. Liquid fuel was introduced through an inlet in the bottom and the fuel level was maintained automatically. The vapor on the free surface of the liquid fuel mixed with the air by natural diffusion as it burned. The fuels used in this burner were 80 octane gasoline, 100/130 aviation gasoline, Air Force Nos. 1010 and 1100 lubricating oils, and petroleum base hydraulic fluid, Mil Spec 0-5606. A 30-in. fan was used to produce wind speeds up to $20 \mathrm{mph}$ at the burner. The areas of these flames projected on a vertical surface, as viewed by the receiver, were estimated to range from 200 to $600 \mathrm{~cm}^{2}$.

Some flames were produced in a ram-jet-type burner, which premixed the vaporized fuel and air and preheated the mixture or injected liquid fuel into preheated air. The fuels were 80 octane gasoline, 100/130 aviation gasoline, and JP-4 jet engine fuel. It was estimated that the projected areas of the jet burner flames, as viewed by the receiver, ranged from 1,000 to $2,500 \mathrm{~cm}^{2}$.

\section{Radiometric Calibration}

The relative spectral response of each of the cells, installed in the instrument without a filter, was measured with a double-quartz-prism spectroradiometer. The relative spectral response of the instrument with a filter (fig. 3) was found by multiplying the relative response of the cell by the transmittance of the filter at each wavelength.

The variation of the response with the irradiance at the receiver was measured. The average deviation from proportionality over the range used was 1.5 to 3 percent of full scale for the four photomultiplier tubes and 4 percent for the lead sulfide cell. To reduce the effect of nonlinearity when the intensities of sources were compared, the viewing distances were chosen so the deflections were approximately the same,

The quantitative significance of the oscillograph deflections was determined by calibration with respect to a standardized mercury-vapor lamp, a General Electric type H 100-A4. The 0.365- $\mu$ line, used to calibrate the photomultiplier tubes, was isolated with a Corning 5860 filter. The $0.578-\mu$ line, used to calibrate the lead sulfide cell, was isolated with a combination of Corning 4784 and 3480 filters.

The intensity of the flame was compared to that of an incandescent lamp, and later the intensity of the incandescent lamp was compared to that of the standard lamp. This indirect procedure was adopted because the standard lamp, which emitted energy of one wavelength, would affect only one section of the instrument unless the filters were removed, whereas the incandescent lamp, with a continuous spectrum, produced a response in all five sections with the filters in place. With the incandescent lamp, calibration traces could be obtained on the oscillograph for all of the cells quickly and conveniently. The filters were removed for the observations on the standard lamp.

As is always the case in abridged spectroradiometry, no single sensitivity could be assigned for the whole interval covered by a cell without taking into account the relative spectral radiance of the source to be observed. Because the relative spectral radiance of the flames was unknown, it was necessary, for purposes of calibration, to assume some spectral radiance curve. For simplicity of analysis, the radiance was taken to be constant and equal to its average value over the wavelength interval involved. In such a case, the response, computed wavelength by wavelength, is the same as that computed by using the average sensitivity over the wavelength range. 
Therefore, the average sensitivity was used for calibration purposes.

If the flame radiance were actually constant with respect to wavelength, the method would be exact. Moreover, it can be shown that if the spectral response of the receiver is symmetrical (a condition roughly approximated in this case in all but one region), the flame radiance need not be constant but merely linearly increasing or decreasing with wavelength. Because diffusion flames, the type usually involved in accidental fires, emit essentially continuous spectra, this method gives results of sufficient accuracy for fire-detector engineering. Measurements on other types of spectra must be interpreted on the basis of the spectral response curves (fig. 3).

\section{Experimental Results}

\subsection{Measured Radiant Intensities}

The measured radiant intensities of several flames, in the five wavelength regions, are given in tables 1 and 2. The tables indicate that some intensities were less than the minimum measurable values. The minimum value depended upon the viewing distance, which was adjusted to keep the largest response within the range of proportionality.

\subsection{Flicker Frequencies}

The flicker amplitude of each flame was recorded for about 20 sec at each of a number of frequencies between 2.5 and 750 cps. The average relative amplitudes, observed at frequencies in the range where there were appreciable amplitudes, are shown for two flames in figures 6 and 7 .

In many cases the flicker amplitude had a sharp maximum at some frequency between 3 and 15 cps, and in some cases the peak amplitude was 100 times the average amplitude over the range from 2.5 to $750 \mathrm{cps}$. In the analysis of one flame that flickered with great regularity, second and third harmonics were observed (see fig. 6). None of the flames observed had appreciable flicker amplitude at frequencies above $150 \mathrm{cps}$, and the jet flames were the only ones having any significant part of the distribution above $25 \mathrm{cps}$. The distributions for the diffusion flames had sharper peaks and higher relative maxima than those for the premixed flames. The most broadly and evenly distributed flicker curves were those for the premixed jet flames, which had maxima only 3 or 4 times the average over a 100-cps band. A wind over the burner increased the amplitude and frequency of flicker of flames on the surface of liquid fuels. The principal flicker maxima were observed at frequencies between 3 and $10 \mathrm{cps}$ for flames on liquids and between 5 and 25 cps for the jet flames.

The ratio of flicker amplitude to the average radiant intensity was determined by measuring the root-mean-square value of the alternating component and the average direct component of the output of the spectroradiometer and taking their ratio. For burning liquids, this ratio ranged from 0.25 for a gasoline fire in a closed room to 0.41 for a hydraulicfluid fire in $20-\mathrm{mph}$ wind. The ratio ranged from

TABLE 1. Radiant intensity of various premixed flames in the jet burner

\begin{tabular}{|c|c|c|c|c|c|c|c|c|c|}
\hline \multirow{2}{*}{$\begin{array}{l}\text { Fuel-air } \\
\text { ratio }\end{array}$} & \multirow{2}{*}{ Fuel rate } & \multirow{2}{*}{\multicolumn{2}{|c|}{ Fuel-air mixture }} & \multirow{2}{*}{$\begin{array}{l}\text { Flame } \\
\text { couple }\end{array}$} & \multicolumn{5}{|c|}{ Radiant intensity (watts per steradian) } \\
\hline & & & & & 0.23 to $0.29 \mu$ & 0.30 to $0.41 \mu$ & 0.41 to $0.55 \mu$ & 0.55 to $0.70 \mu$ & 0.70 to $2.5 \mu$ \\
\hline \multicolumn{10}{|c|}{ Gasoline and air premixed and preheated } \\
\hline $\begin{array}{r}0.0473 \\
.0479 \\
.0702 \\
.1062 \\
.0984\end{array}$ & $\begin{array}{c}l b / \min \\
1.41 \\
4.53 \\
6.60 \\
3.27 \\
6.60\end{array}$ & $\begin{array}{l}{ }^{\circ} F \\
300 \\
300 \\
300 \\
300 \\
300\end{array}$ & $\begin{array}{c}\mathrm{ft} / \mathrm{sec} \\
137 \\
397 \\
397 \\
144 \\
294\end{array}$ & $\begin{array}{c}\circ F \\
2,520 \\
2,290 \\
3,390 \\
2,810 \\
3,150\end{array}$ & $\begin{array}{c}0.0026 \\
.0061 \\
.028 \\
.032 \\
.037\end{array}$ & $\begin{array}{l}0.069 \\
.14 \\
1.0 \\
0.78 \\
1.2\end{array}$ & $\begin{array}{c}0.046 \\
.090 \\
.95 \\
.98 \\
1.9\end{array}$ & $\begin{array}{c}<0.001 \\
<.001 \\
.50 \\
.51 \\
1.04\end{array}$ & $\begin{array}{r}21 \\
14 \\
(\mathrm{a}) \\
(\mathrm{a}) \\
157\end{array}$ \\
\hline \multicolumn{10}{|c|}{ Gasoline injected into preheated air } \\
\hline $\begin{array}{r}0.0460 \\
.0471 \\
.0470\end{array}$ & $\begin{array}{l}2.32 \\
3.14 \\
4.43\end{array}$ & $\begin{array}{l}\text { b } 113 \\
115 \\
121\end{array}$ & $\begin{array}{r}\text { b } 171 \\
221 \\
301\end{array}$ & $\begin{array}{l}2,150 \\
2,600 \\
2,850\end{array}$ & $\begin{array}{r}0.18 \\
.20 \\
.21\end{array}$ & $\begin{array}{r}0.26 \\
.27 \\
.61\end{array}$ & $\begin{array}{r}0.49 \\
.52 \\
.70\end{array}$ & $\begin{array}{l}3.2 \\
2.3 \\
1.7\end{array}$ & $\begin{array}{l}233 \\
175 \\
265\end{array}$ \\
\hline
\end{tabular}

a Not measured. bAir temperature and velocity.

TABLE 2. Radiant intensity of various diffusion flames in the six-inch cylindrical burner

\begin{tabular}{|c|c|c|c|c|c|c|c|}
\hline \multirow{2}{*}{ Fuel } & \multirow{2}{*}{ Fuel rate } & \multirow{2}{*}{$\begin{array}{l}\text { Wind } \\
\text { speed }\end{array}$} & \multicolumn{5}{|c|}{ Radiant intensity (watts per steradian) } \\
\hline & & & 0.23 to $0.29 \mu$ & 0.30 to $0.41 \mu$ & 0.41 to $0.55 \mu$ & 0.55 to $0.70 \mu$ & 0.70 to $2.5 \mu$ \\
\hline $\begin{array}{l}\text { Gasoline } \\
\text { Do } \\
\text { Hydraulic fluid } \\
\text { Do } \\
1100 \text { lube oil } \\
\text { Do }\end{array}$ & $\begin{array}{l}l b / \min \\
0.053 \\
.16 \\
.017 \\
.072 \\
.025 \\
.030\end{array}$ & $\begin{array}{c}m p h \\
0 \\
20 \\
0 \\
20 \\
0 \\
10\end{array}$ & $\begin{array}{l}<1 \times 10^{-4} \\
<1 \times 10^{-4} \\
<1 \times 10^{-4} \\
<1 \times 10^{-4} \\
<1 \times 10^{-4} \\
<1 \times 10^{-4}\end{array}$ & $\begin{aligned} & 2.2 \times 10^{-2} \\
& 1.8 \times 10^{-2} \\
&<1 \times 10^{-5} \\
& 2.6 \times 10^{-2} \\
& 6.7 \times 10^{-5} \\
& 1.8 \times 10^{-2}\end{aligned}$ & $\begin{array}{l}0.21 \\
1.5 \\
0.0032 \\
.095 \\
.0087 \\
.88\end{array}$ & $\begin{array}{l}2.1 \\
4.3 \\
0.71 \\
5.2 \\
0.22 \\
5.0\end{array}$ & $\begin{array}{r}21 \\
176 \\
237 \\
303 \\
31 \\
135\end{array}$ \\
\hline
\end{tabular}




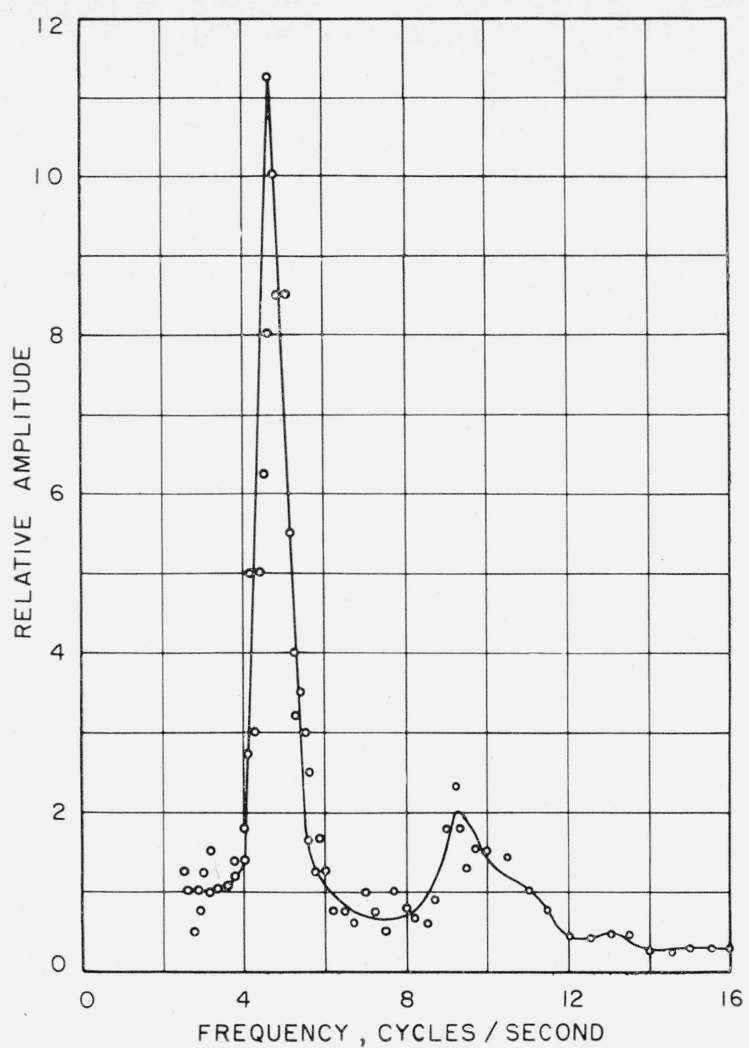

Figure 6. Wave analysis of natural-gas diffusion flame.

0.05 to 0.15 for premixed jet flames and from 0.1 to 0.3 for the flames resulting from liquid-fuel injection.

\subsection{Rate of Increase of Radiant Intensity}

The rate of increase in the infrared radiant intensity, just after ignition, was measured, using diffusion flames on gasoline and hydraulic fluid in the 6-in. burner. Figure 8 shows a typical record of the radiant intensity of a gasoline diffusion flame from the instant of ignition, together with a 40-cps timing trace. The first maximum occurred about $0.2 \mathrm{sec}$ after ignition of gasoline fires and about 0.3 sec after ignition of hydraulic-fluid fires. In many cases the successive maxima increased gradually for a few seconds, presumably as a result of an increased rate of evaporation of the liquid fuel upon heating.

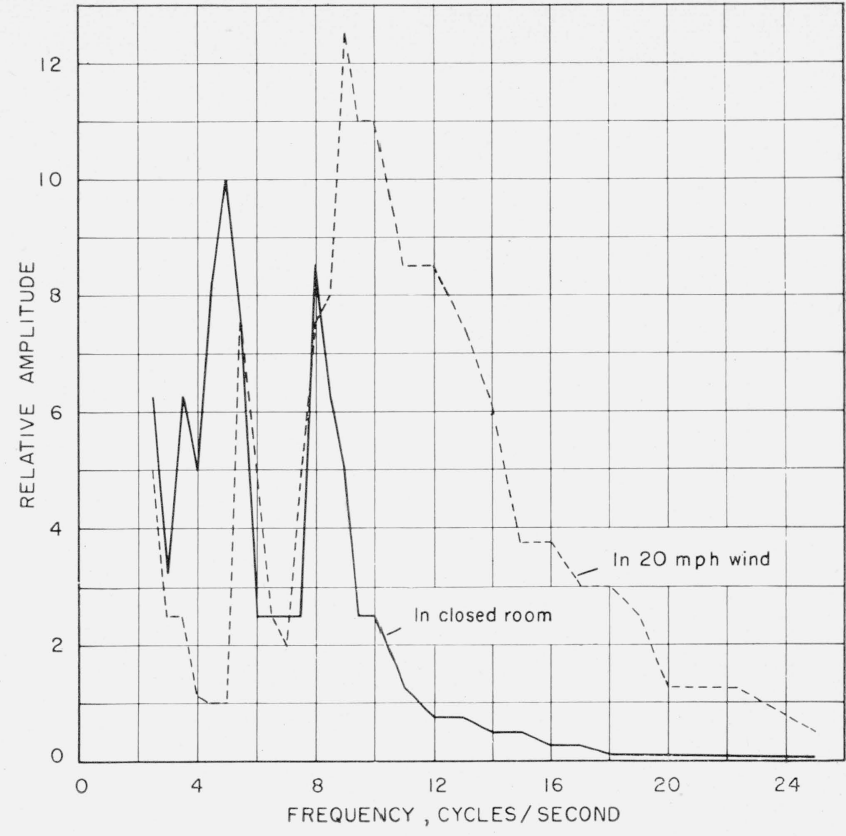

Figure 7. Wave analysis of gasoline diffusion flame.

Generally, the first recorded maximum value was about the same as the average steady-state value; consequently, the approximate initial rate of increase in the radiant intensity may be calculated by dividing the values reported in table 2 by 0.2 in the case of gasoline or 0.3 in the case of hydraulic fluid.

Using a radiation pyrometer [6] as a receiver, and Pyrex, quartz, and fluorite lenses and filters, some measurements were made in the spectral regions extending to $2.5,3.6$, and $9.5 \mu$. Only about 10 percent of the energy from premixed flames and 30 to 50 percent of the energy from diffusion flames was found in the region covered by the spectroradiometer. This must be kept in mind when considering the data presented here.

The observation that the flicker occurs in the various regions of the spectrum with practically the same amplitude and frequency indicates that flicker detectors need not necessarily operate in a restricted wavelength interval. The ratio of the flicker amplitude to the average radiant intensity should be of value in the design of flicker discriminating cir-

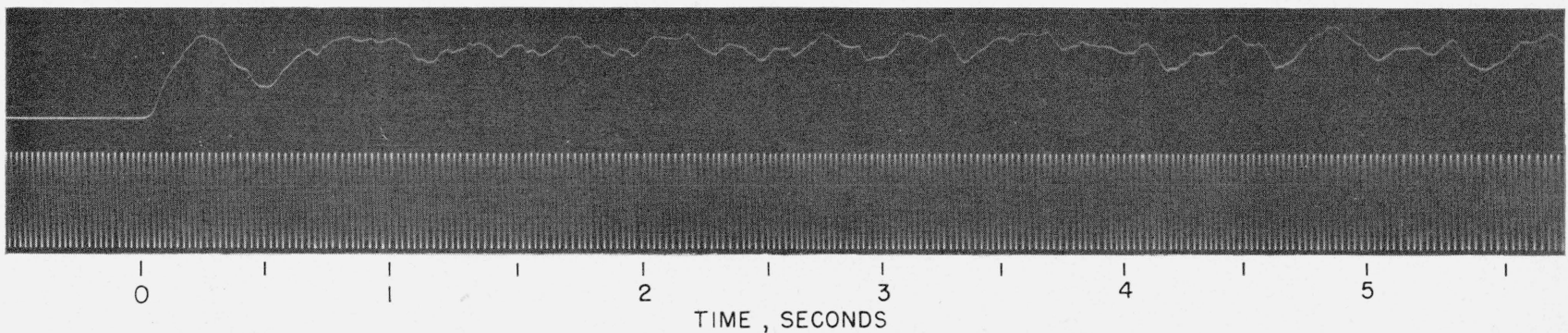

FIGURE 8. Oscillograph record of radiant intensity of a gasoline diffusion flame during several seconds after ignition and a 40 -cps timing trace. 
cuitry. Information concerning the amount of energy in the various parts of the spectrum should aid in designing for discrimination on the basis of spectral distribution. The characteristic rate of increase in radiant intensity upon ignition of the fires studied appears to be a valuable discriminating criterion heretofore overlooked.

Although the instrument described was designed, built, and used to solve a particular problem, its rapid response and the ease with which the wavelength regions could be changed suggest the possibility of its application to other problems. By the use of narrow-band filters, the instrument could produce a continuous record of the intensity of selected spectral lines or bands. With suitable broadband filters for the visible region, the instrument could be used to obtain data on rapidly changing color phenomena. The ultraviolet sensitivity of the instrument suggests possible applications in fluorescence measurements.
Among those who assisted with this work were C. F. Mijal, who synthesized the perchlorate used in the liquid filter, and W. F. Roeser, the leader of the project of which this work was a part.

\section{References}

[1] P. B. Weisz, Automatic fire alarm, U. S. Patent No. 2,507,359 (May 9, 1950).

[2] E. D. Reddan, Electronic eye spots engine fires, Aviation Age 24, 150 (Oct. 1955).

[3] A. G. Gaydon and H. G. Wolfhard, Flames (Chapman and Hall, Ltd., London, 1953).

[4] M. Kasha, Transmission filters for the ultraviolet, J. Opt. Soc. Am. 38, 929 (1948).

[5] The Naval Ordnance Laboratory six-trace cathode-ray oscillograph, AIEE Technical Paper 48-217.

[6] Temperature, its measurement and control in science and industry (Reinhold Publishing Corp., New York, N. Y., 1941).

WAshington, January 9, 1956. 